\title{
Effects of Chia Supplementation on Meat Fat Quality
}

\author{
Jorge Arturo Santos López ${ }^{1 *}$ and Rafael Gómez Moreno ${ }^{2}$ \\ ${ }^{1}$ Department of Pharmacology, Pharmacognosy and Botany, Complutense University of Madrid. Spain \\ ${ }^{2}$ Las Calesas Primary Care Health Center. Spain
}

Submission: February 28, 2019; Published: March 07, 2019

*Corresponding author: Jorge Arturo Santos López, Department of Pharmacology, Pharmacognosy and Botany, Complutense University of Madrid. Plaza Ramón y Cajal w/n, 28040, Madrid, Spain

\begin{abstract}
While plant-based diet has gain recognition for its health benefits, meat and meat products are still one of the most consumed foods in western countries. Meat is an important source of proteins, minerals, and vitamins. Nonetheless, its consumption has been associated with degenerative diseases, mainly related to its fat content. Although there has been a general recommendation against some kinds of dietary fat consumption over the years, there is a lack of information regarding the different techniques of breeding and feeding animals intended for food that could lead to diverse health effects after their consumption. In the process of obtaining healthier meat products, a number of modifications could be made to add, reduce, or increase substances with proven biological properties (functional ingredients). In this regard, interest in polyunsaturated fatty acids, such as $\alpha$-linolenic acid (ALA), has become a nutrition research target. The chia seeds are one of the richest sources of ALA and contain high amounts of fiber and minerals. Although studies on the bioavailability of essential nutrients in Chia have not been fully described, based on the compositional data from all reported studies it could be considered that chia seeds are nutritionally valuable. Moreover, the chia-enriched meat and meat products have demonstrated a positive effect in the regulation of lipid metabolism, and the human trials have proved the beneficial effect on lipid composition and lipemia regulation in patients with moderately cholesterolemia.
\end{abstract}

Keywords: Meat; Meat fat; Chia; Chia seed; Omega-3; ALA; PUFA

Abbreviations: ALA: $\alpha$-Linolenic Acid; CVD: Cardiovascular; PUFA: Polyunsaturated Fatty Acids; EPA: Eicosapentaenoic Acid; DPA: Docosapentaenoic Acid; SFA: Saturated Fatty Acids; MUFA: Monounsaturated Fatty Acids

\section{Introduction}

Changes in human diets throughout time, mainly related to dietary fat intake, have become a major interest in nutrition research [1]. While plant-based diet has gain recognition for its health benefits, meat and meat products are still one of the most consumed foods in western countries [2]. Due to its high nutritional value, meat plays a central role in human development. It is an important source of proteins, minerals, and vitamins. Nonetheless, its consumption has been associated with degenerative diseases, mostly because of its fat content and composition, such as metabolic syndrome, cardiovascular (CVD) and neurological diseases, or cancer [3-6].

Although there has been a general recommendation against some kinds of dietary fat consumption over the years, there is a lack of information regarding the different techniques of breeding and feeding animals intended for food that could lead to diverse health effects after the consumption of their meat, eggs, or dairy products [7]. Multiple studies have shown that meat products from animals feed pasture instead of grains contain significantly higher amounts of health-beneficial nutrients, like omega-3 fatty acids [7-9].

In the process of obtaining healthier meat products, a number of modifications could be made to add, reduce, or increase substances with proven biological properties (functional ingredients) $[10,11]$. In this regard, interest in polyunsaturated fatty acids (PUFA), such as $\alpha$-linolenic acid (ALA), has become a nutrition research target. However, ALA is not readily available as there are few foods that can provide adequate amounts to obtain the benefits associated with its consumption [12]. The seeds of Salvia hispanica L., commonly known as chia, are one of the richest sources of ALA and contain high amounts of fiber and minerals $[12,13]$. Chia seed lipid content varies from $20 \%$ to $40 \%$, with $60 \%$ of total lipids comprising ALA and $20 \%$ of linoleic acid $[11,13]$. The extracted oil contains $34 / 100 \mathrm{~g}$ of dietary fiber and $17 / 100 \mathrm{~g}$ of protein [11]. Chia oil is also rich in magnesium and 
phenolic compounds (quercetin and kaempferol). As functional ingredient, besides its effects associated to PUFA, chia seed has proved to be a potent antioxidant $[11,14]$; and its calcium and potassium content suggests positive influence on high blood pressure [15].

\section{Chia Effect on Meat Fat Quality}

The use of chia and its derivatives in animal feed has become an interesting tool when improving meat products. Besides the application of chia in animal targeted for human consumption, it had also been used for animal nutrition by itself [16]. There are two main eight-week studies carried out in laying hens or broiler chickens. The purpose of these studies was to assess the effects of Chia on the composition of egg yolk lipids and egg acceptability in comparison with other omega-3 sources. In the first study, a total of 32 animals received diets with four different $\alpha$-tocopherol contents containing $14.0 \%$ whole Chia seeds corresponding to a dose of $16.8 \mathrm{~g} /$ day. The control groups were fed with isoenergetic diets added with $1.5 \%$ soya oil or $1.5 \%$ fish oil. These results proved that the inclusion of Chia seeds in the diet reduced the content of C16:0, C18:1 and total $n-6$ fatty acids in eggs whereas the content of total $n-3$ fatty acids was increased.

There was no adverse effect on egg yolk lipid oxidative stability with any of the dietary treatments. In the second study, 32 hens were fed a diet with $15 \%$ whole Chia seeds corresponding to a dose of $18.2 \mathrm{~g} /$ day. This study demonstrate that Chia seeds were more effective in modifying egg yolk fatty acid composition compared with the control group that was fed diets with whole linseeds or linseed oil. There were no differences in egg quality and no adverse effects in the animals [13]. These studies have also analyzed the effect of chia supplementation on the fatty acid content of breast and thigh muscle of broilers and the sensory attributes of these products. The animals received diets with $10 \%$ Chia for 28 days. According to the researchers, deposition of linolenic acid was significantly increased in the breast meat of birds fed the Chia-supplemented diet compared with control animals. There were no significant differences in performance and sensory attributes [13].

The studies performed by Ayerza and Coates $[5,6,17]$ evaluate the effect of diets containing $7,14,21$, and $28 \%$ Chia seeds in four hundred for 49 days, and fifty laying hens for 90 days. Cholesterol and total fat content, and yolk fatty acid profile were determined. The results proved a significant reduction on cholesterol and total saturated fatty acid content as the Chia amounts and time of the study increased. The total PUFA and omega- 3 contents were significantly higher for Chia diets when compared with control diet [5]. Cholesterol content was not significantly different between chia treatments; however, the $10 \%$ Chia diet produced a lower fat content in the dark meat when compared to the control diet. Chia also significantly reduced the saturated fatty acid content as well as the omega-6: omega- 3 ratio of the white and dark meats when compared to the control diet. The flavor or preference ratings did not present any significant differences between groups. Body weight and feed conversion were significantly lower with the Chia diets than with the control, with weight reductions up to $6.2 \%$ in the 20 $\%$ Chia diet, also manure production was lower for the animals fed Chia and a reduction in yolk production was found [6]. No significant differences in egg production were found between the different treatments. In the 4-week study with 24 laying hens, a $30 \%$ Chia content diet did not present significant differences when compared to control diet in yolk fat content. The levels of palmitic fatty acid in yolks were less with the Chia diet and ALA content was higher. Egg production was lower in this groups when compared to control, however there was no difference on egg weights [17].

The study by Meineri [18] evaluated the effects of Chia seed supplementation on rabbit meat quality, oxidative stability and sensory traits. The animals were fed isocaloric and isonitrogenous enriched diets with 0,10 , and $15 \%$ of chia seeds. The results shown a complete description of the performance and carcass characteristics, and the fatty acid composition of the fat of thirty carcasses obtained from three groups of ten crossbred rabbits. The authors concluded that chia seed supplementation did not cause any adverse effects on meat quality or consumer acceptability. Also, that the inclusion of $15 \%$ chia seed in the rabbit diets increased the lipid oxidation at the ground hind leg meat during conservation, mainly due to a concurrent enlargement of PUFA [18]. Similar results were obtained by Peiretti [19], with 0, 10 and 15\% Chia seed-enriched diets fed to thirty weaned crossbred rabbits. The results shown that chia supplementation is well accepted by animals at levels of up to $15 \%$ of the diet without any adverse effects on growth performance or carcass characteristics. The chia supplementation is effective in improving the omega-3 content, decreasing the omega-6/ omega-3 3 ratio and reducing the saturation, atherogenic and thrombogenic indexes of the rabbit meat, with resulting benefits on its nutritional quality [19].

Urrutia [20] evaluated the effect of chia seed supplementation on growth and carcass parameters and fatty acid composition in the adipose tissue in lambs. This study was developed with thirty-one male Navarra breed lambs and fed one control diet of barley and soybean and the $10 \%$ chia seed diet for 4 weeks. The results showed that supplementing lambs' diet with chia seed had no effect on the growth parameters. Although it increased the adipose tissue content of ALA, eicosapentaenoic acid (EPA), docosapentaenoic acid (DPA), and total omega-3 fatty acid contents; and decreased the omega-6/omega-3 ratio [20].

Although there is a lack of studies evaluating the chia supplementation on pig and cattle, there are many other evaluating the nutritional and physiological effect of meat and meat derivatives containing chia. The rodent studies performed by Santos-López [11,21] have demonstrated the beneficial effects of chia oil pork-enrichment on lipoprotein 
metabolism, oxidation and inflammation statuses in the frame of an atherogenic diet. These studies stress the importance of the omega- 3 incorporation into the diet and the positive effect when consuming meat derivatives $[11,21]$. The study performed by Adams 22] evaluated the effects human health of high saturated fatty acids (SFA) versus high monounsaturated fatty acids (MUFA) beef. The SFA beef was produced with grass-fed cattle and the MUFA with conventionally fed cows. Then, 10 mildly hypercholesterolemic subjects were indicating to eat 114 $\mathrm{g}$ beef per week for five weeks. The serum lipids were measured. Results showed a significant increase in triglycerides and HDLcholesterol in the group that consumed meat from grass-fed cows $[7,22]$.

McAfee [23] compared grass-fed and grain-fed red meat intake on serum omega-3 PUFA and analyzed the produced changes in blood lipids. In a double-blind study, 38 healthy volunteers were divided into two groups and request to eat $470 \mathrm{~g}$ red meat per week for four weeks. Meat samples were grass fed versus conventional. The grass-fed meat group demonstrated significant increases in serum DHA, EPA, and total omega-3 content when compared with the control group $[7,23]$.

\section{Conclusion}

Although studies on the bioavailability of essential nutrients in Chia have not been fully described and evaluated up to the moment of this publication, based on the compositional data from all reported studies in animals it could be considered that chia seeds are nutritionally valuable under the proposed conditions of use. Moreover, the chia-enriched meat and meat products have demonstrated a positive effect in the regulation of lipid metabolism, and the human trials have proved the beneficial effect on lipid composition and lipemia regulation in patients with moderately cholesterolemia.

\section{Conflict of interests}

The authors declare no conflict of interests.

\section{References}

1. Simopoulos AP (1998) Overview of evolutionary aspects of w3 fatty acids in the diet. World review of nutrition and dietetics 83: 1-11.

2. Mann NJ (2018) A brief history of meat in the human diet and current health implications. Meat science 144: 169-179.

3. Okuyama H, Kabayeshi T, Watanabe S (1997) Dietary fatty acids the n-6/n-3 balance and chronic diseases. Prog Lip Res 35: 217-244.

4. Katan MB, Zock PL, Mensink RP (1995) Dietary oils, serum lipoproteins, and coronary heart disease. The American journal of clinical nutrition 61: 1368S-1373S.

5. Ayerza R, Coates W (2000) Dietary levels of chia: Influence on yolk cholesterol, lipid content and fatty acid composition for two strains of hens. Poultry science 79: 724-739.

6. Ayerza R, Coates W, Lauria M (2002) Chia seed (salvia hispanica l.) as an omega-3 fatty acid source for broilers: Influence on fatty acid composition, cholesterol and fat content of white and dark meats, growth performance, and sensory characteristics. Poultry Science 81: 826-837.
7. Haskins CP, Henderson G, Champ CE (2018) Meat, eggs, full-fat dairy, and nutritional boogeymen: Does the way in which animals are raised affect health differently in humans? Critical reviews in food science and nutrition p. 1-11.

8. Daley CA, Abbott A, Doyle PS, Nader GA, Larson S (2010) A review of fatty acid profiles and antioxidant content in grass-fed and grain-fed beef. Nutrition Journal 9: 10.

9. French P, Stanton C, Lawless F, O'riordan E, Monahan F, et al. (2000) Fatty acid composition, including conjugated linoleic acid, of intramuscular fat from steers offered grazed grass, grass silage, or concentrate-based diets. Journal of animal science 78: 2849-2855.

10. Arihara K (2006) Strategies for designing novel functional meat products. Meat science 74: 219-229.

11. Santos López JA, Garcimartín A, López Oliva ME, Bautista Avila M, González Muñoz MJ, et al. (2017) Chia oil-enriched restructured pork effects on oxidative and inflammatory status of aged rats fed high cholesterol/high fat diets. Journal of medicinal food 20: 526-534.

12. Valenzuela R, Barrera C, González Astorga M, Sanhueza J, Valenzuela A (2014) Alpha linolenic acid (ala) from rosa canina, sacha inchi and chia oils may increase ala accretion and its conversion into n-3 lcpufa in diverse tissues of the rat. Food \& function 5: 1564-1572.

13. EFSA (2009) Opinion on the safety of 'chia seeds (salvia hispanica l.) and ground whole chia seeds' as a food ingredient. EFSA Journal 7: 996.

14. Reyes Caudillo E, Tecante A, Valdivia López M (2008) Dietary fibre content and antioxidant activity of phenolic compounds present in mexican chia (salvia hispanica l.) seeds. Food Chemistry 107: 656-663.

15. Vuksan V, Whitham D, Sievenpiper JL, Jenkins AL, Rogovik AL, et al. (2007) Supplementation of conventional therapy with the novel grain salba (salvia hispanica l.) improves major and emerging cardiovascular risk factors in type 2 diabetes: Results of a randomized controlled trial. Diabetes Care 30: 2804-2810.

16. Mohd Ali N, Yeap SK, Ho WY, Beh BK, Tan SW, et al. (2012) The promising future of chia, salvia hispanica l. BioMed Research International, p. 9.

17. Ayerza R, Coates W (1999) An $\omega-3$ fatty acid enriched chia diet: Influence on egg fatty acid composition, cholesterol and oil content. Canadian Journal of Animal Science 79: 53-58.

18. Meineri G, Cornale P, Tassone S, Peiretti PG (2010) Effects of chia (salvia hispanica l.) seed supplementation on rabbit meat quality, oxidative stability and sensory traits. Italian Journal of Animal Science 9: e10.

19. Peiretti P, Meineri G (2008) Effects on growth performance, carcass characteristics, and the fat and meat fatty acid profile of rabbits fed diets with chia (salvia hispanica l.) seed supplements. Meat Science 80: 1116-1121.

20. Urrutia O, Soret B, Insausti K, Mendizabal J, Purroy A, et al. (2015) The effects of linseed or chia seed dietary supplementation on adipose tissue development, fatty acid composition, and lipogenic gene expression in lambs. Small Ruminant Research 123: 204-211.

21. Santos López JA, Garcimartín A, Bastida S, Bautista-Ávila M, GonzálezMuñoz MJ, et al. (2018) Lipoprotein profile in aged rats fed chia oil-or hydroxytyrosol-enriched pork in high cholesterol/high saturated fat diets. Nutrients 10: 1830.

22. Adams TH, Walzem RL, Smith DR, Tseng S, Smith SB (2010) Hamburger high in total, saturated and trans-fatty acids decreases hdl cholesterol and ldl particle diameter, and increases tag, in mildly hypercholesterolaemic men. British Journal of Nutrition 103: 91-98.

23. McAfee A, McSorley E, Cuskelly G, Fearon A, Moss B, et al. (2011) Red meat from animals offered a grass diet increases plasma and platelet n-3 pufa in healthy consumers. British Journal of Nutrition 105: 80-89. 
CC This work is licensed under Creative Commons Attribution 4.0 License DOI: 10.19080/JDVS.2019.10.555791

\section{Your next submission with Juniper Publishers} will reach you the below assets

- Quality Editorial service

- Swift Peer Review

- Reprints availability

- E-prints Service

- Manuscript Podcast for convenient understanding

- Global attainment for your research

- Manuscript accessibility in different formats

( Pdf, E-pub, Full Text, Audio)

- Unceasing customer service

Track the below URL for one-step submission https://juniperpublishers.com/online-submission.php 